\section{A New Technique for the Viable Count of Bacteria}

THE general principle followed so far for the viable count of bacteria in a suspension is either to count the number of colonies produced by a very dilute suspen. sion of bacteria on an agar plate ${ }^{1}$ or to observe the differential staining behaviour of the living bacterium to distinguish it from the dead one $e^{2}$ No reliable technique has yet been recorded for identifying viable cells in a mixed suspension of viable and non-viable bacteria when counting under the microscope. I have been able to identify living bacteria during the counting process by the hæmatocytometer method.

In this technique, bacteria were grown in the nutrient broth, to 100 c.c. of which $1 \mathrm{gm}$. of $2,3,5$ triphenyltetrazolium hydrochloride was added. Bacteria were inoculated on nutrient agar slants and after incubation for $18 \mathrm{hr}$. they were washed with 5 c.c. sterile nutrient broth. The number of bacteria per cubic centimetre in this slant-washed suspension was counted. The nutrient broth with the tetrazolium salt was inoculated with 1 c.c. of that suspension and incubated at $37^{\circ} \mathrm{C}$. After incubation for $1 \mathrm{hr}$., the number of bacteria in the broth was counted with the conventional hæmatocytometer, using 4 per cent formalin as diluting fluid. Formalin kills the bacteria and at the same time fixes them. Moreover, formalin does not impair the effect of tetrazolium salt in staining the bacteria. The killed and fixed bacteria were counted with the ordinary light microscope having objective with 0.65 N.A. and $12 \times$ eyepiece. The living bacteria were observed to have a reddish tinge whereas the dead cells were completely transparent. The fact that the stained cells were alive was proved by their ability, before treatment with formalin, to produce a colony when inoculated, whereas the unstained bacteria did not develop any colonies. The simple growth curve of the viable and total count of $E$. coli ( $G$ strain) in nutrient broth by this method up to $12 \mathrm{hr}$. of growth is shown in Fig. 1 .

In this technique, tetrazolium salt was used on the assumption that the mitochondria of living bacteria would reduce the salt in red formazan bodies ${ }^{3}$, whereas in the dead bacteria, enzymatic activities of the mitochondria would be impaired and consequently formation of the red formazan particles would not occur. Under the microscope, the reddish stain which the viable cells exhibited was, in fact, due to these red formazan bodies. Moreover, tetrazolium salt did not produce any toxic effect to the bacteria so the rate of growth of the culture was not retarded. This was proved by a control experiment using the nutrient broth without adding tetrazolium salt to it.

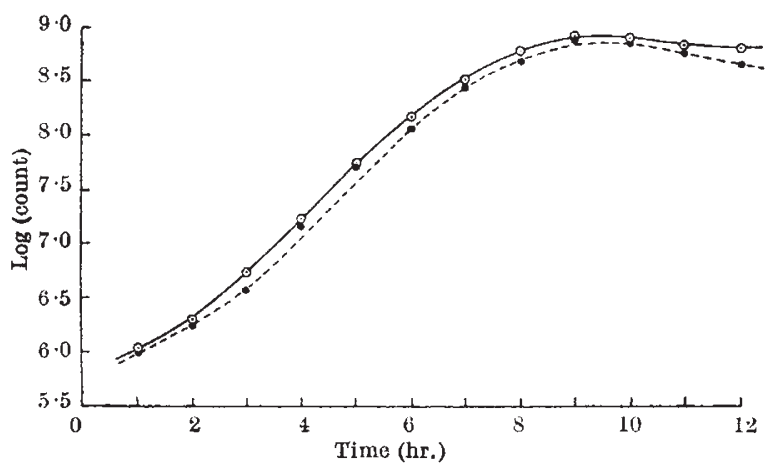

Fig. 1. Growth of Escherichia coli ( $G$ strain) in broth. Continuous line represents total count and interrupted line the count of
Thus it is possible to use the tetrazolium salt for counting the viable cells along with the total count of bacteria in a suspension.

I thank Prof. N. N. Das Gupta for his interest in the work; and I am indebted to Mr. K. N. Bhattacharya for helping in some preparatory aspects of the work.

Biophysics Division,

A. GOHA

Institute of Nuclear Physics, Calcutta-9. Jan. 28.

${ }^{1}$ Miles, A. A., and Misra, S. S., J. Hyg., Camb., 38, 732 (1938), Wilson, G. S., J. Bact., Y, 405 (1922).

${ }^{2}$ Gay, F. P., and Clark, A. R., J. Bact., 27, 175 (1934). Knaysi, G., J. Bact., 30, 193 (1935).

${ }^{3}$ Weibull, C., J. Bact., 66, 137 (1953)

\section{A Simple Spore Trap}

WHEN studying an air-borne plant pathogenic fungus, it is often desirable to determine whether the spores of the organism are present in the atmosphere at particular times. When accurate data suitable for statistical analysis are required, the use of apparatus such as the Hirst ${ }^{1}$ spore trap is desirable. However, lack of funds or the absence of need for elaborate data may preclude such a purchase. The alternative would seem to consist of placing suitably treated microscope slides in a fixed position-a method known to be relatively inefficient. In seeking a compromise, the following spore trap was designed.

Three main considerations were involved in the construction of a suitable apparatus. First, it was desirable that a volume of air larger than normal be permitted to pass over the surface of microscope slides. Secondly, it was necessary to ensure that at all times the slides would face into the wind; and thirdly, the air must pass over the surface of the slides free from turbulence, thus facilitating the deposition of the spores on suitably treated slides. The design finally adopted was evolved by experimentation and consideration of aeronautical problems.

The apparatus was constructed in aluminium and consisted of a convergent cone, which faced into the wind, leading into a divergent cone of similar size. The leading edge of the convergent cone had an internal diameter of $7 \frac{1}{2}$ in., narrowing down to a diameter of $3 \frac{3}{4}$ in. over a 12 -in. length. At this point the diameter remained constant for a length of 2 in. and gave a smooth slide fit into the rear half collar of the divergent cone.

A slotted holder for two $3 \mathrm{in.} \times 1$ in. microseope slides was mounted in the central 2 -in. area in such a way that the slides were held in a constant position, tilted at an angle of $30^{\circ}$ to the horizontal.

Two wind vanes were mounted vertically in a central position on the top and bottom of the rear divergent cone and their weight was counter-balanced by addition of a reinforcing ring on the front cone.

The cones were mounted on a relatively short pivot spindle which ended in a $60^{\circ}$ angle point. The last 6 in. of the spindle fitted inside a pipe of slightly larger diameter with the point resting in the centre of a $90^{\circ}$ angle seat so that there was a $30^{\circ}$ angle difference between the angle of the cone-shaped point of the spindle and its seat. The space between the spindle and the slightly wider-bore pipe was filled with oil to allow the spindle to rotate freely. With this design it was found that the cones were extremely sensitive to even the slightest changes of wind of very low velocity. 